\title{
Buchanan clubs
}

\author{
Todd Sandler
}

Published online: 13 November 2013

(C) The Author(s) 2013. This article is published with open access at Springerlink.com

\begin{abstract}
This article evaluates the contribution of James M. Buchanan's theory of clubs. At the outset, the article distinguishes club goods from pure public goods. Next, the article distills the basic mathematical structure of Buchanan's treatment of clubs. This is followed by some key variants of Buchanan clubs. More general formulations of club theory are also addressed. To demonstrate the wide-ranging importance of Buchanan clubs, the article indicates varied applications of club theory. The article's message is that club theory remains highly relevant today.
\end{abstract}

Keywords Buchanan clubs - Club applications - Exclusion mechanisms · Public goods

JEL Classification $\quad$ D7 $\cdot \mathrm{H} 4 \cdot \mathrm{H} 8$

\section{Introduction}

In his seminal article, "An Economic Theory of Clubs," Buchanan (1965) introduced the analysis of club goods to bridge the chasm between private and pure public goods. For private goods, consumption rivalry and exclusion are complete, while for pure public goods, consumption is nonrivalrous and exclusion is not possible. ${ }^{1}$ Nonexcludability of nonpaying benefit recipients leads to the free-rider

\footnotetext{
${ }^{1}$ A good's benefits are nonrival when a unit of the good can be consumed by one individual without detracting, in the slightest, from the consumption opportunities still available for others from the same unit. Nonrivalry means that the marginal cost of extending the good's benefits to another consumer is zero. If the benefits of a good are available to all once the good is supplied, then its benefits are nonexcludable.
}

T. Sandler (ه)

Department of Economics, School of Economic, Political and Policy Sciences, University of Texas at Dallas, $800 \mathrm{~W}$. Campbell Road, Richardson, TX 75080, USA

e-mail: tsandler@utdallas.edu 
problem, which requires government provision of pure public goods. Buchanan (1965) envisioned clubs as a member-owned institutional arrangement for the provision of a club good that is subject to some rivalry in the form of congestion. Crowding or congestion involves a detraction in a club good's quantity or quality from increased utilization by the sharers-e.g., higher bacteria counts in swimming pools, longer queues at amusement parks, or slower transits on bridges. The presence of congestion means that the extension of user rights to another individual implies a nonzero marginal cost, which, in turn, justifies the need to restrict users or members. In contrast, there is no need to restrict the number of consumers for a nonrivalrous good, because society prospers from extending consumption to anyone who obtains a positive marginal benefit.

The origins of "club theory" predates Buchanan's (1965) seminal article. Tiebout (1956) put forward a "voting-with-the-feet" hypothesis, whereby a population partitions itself among jurisdictions so as to match individuals' tastes with local public good and taxation options. In a private good context, Wiseman (1957) formulated a club principle for sharing costs among users of a public utility, while Olson (1965) put forward the notion of exclusive groups for sharing an impure public good. For exclusive collectives, membership size must be determined for the shared good, but Olson (1965) never used the term, club. Finally, early studies of highway congestion and tolls (e.g., Mohring and Harwitz 1962) addressed the sharing of an impure public good, where tolls internalized congestion and effectively fixed membership in terms of toll-paying users. For the forerunners of club theory, the interface between the provision of the shared good and membership is not clear, because provision is exogenous, which is not the case for Buchanan clubs.

Buchanan's club theory holds an exalted place in the study of public choice for a number of reasons. First, club theory can serve as the theoretical foundation for jurisdictional design, because this theory can be made to capture the provision, membership, and partitioning decisions associated with the earlier Tiebout hypothesis (McGuire 1974; Pauly 1967). Tiebout's (1956) celebrated article did not provide a formal model for his insightful thought-experiment. Second, Buchanan's club theory emphasizes that public goods may, under key circumstances, be provided privately, so that public goods need not imply government provision. Third, club theory indicates that membership size or the number of sharers is an endogenous choice that is not independent of the provision decision. Fourth, the study of clubs can be applied to an amazing array of situations that include treaty formation, military alliances, wilderness areas, cities, roads, antibiotic use, the Internet, international organizations, and customs unions. In fact, the study of clubs impacts virtually every field of economics in some way-e.g., labor economics (labor unions), international economics (free-trade areas), urban economics (road provision), monetary economics (monetary unions), sports economics (the size of leagues), public finance (impure public goods), environmental economics (national parks and forest preserves), and health economics (public-private partnership for disease control).

Even though Buchanan's (1965) club article generated literally hundreds of articles (Sandler and Tschirhart 1980, 1997), he devoted only a single article to the 
topic, leaving others to model and analyze myriad refinements to the study of clubs. These refinements concerned the optimality of clubs, alternative institutional forms for clubs, the number of clubs, the composition of members, the form of the congestion function, the type of exclusion mechanism, and the financing of clubs. Buchanan deftly laid the foundation to club theory in a simple, but efficient framework, and then moved on.

The primary purpose of this article is to characterize the essential structure of the Buchanan theory of clubs. In so doing, I indicate how the simple structure of Buchanan clubs paved the way for myriad follow-up articles. Thus, this article presents many aspects of club theory, not captured in Buchanan (1965). A secondary purpose is to provide the reader with an appreciation of why club theory is still studied today.

The remainder of the article contains six sections. Section 2 distinguishes club goods from other public goods, to show how Buchanan addressed the chasm between private and pure public goods. In Sect. 3, the theoretical structure of Buchanan clubs is displayed. Key variants of Buchanan clubs are analyzed in Sect. 4, followed by a discussion of more general formulations in Sect. 5. Varied and broad-reaching applications are given in Sect. 6. Finally, Sect. 7 contains concluding remarks.

\section{Club goods versus other public goods}

A club is a voluntary group deriving mutual benefits from sharing one or more of the following: production costs, the members' characteristics, or a good characterized by excludable benefits (Sandler and Tschirhart 1980). Buchanan (1965) focused on clubs that share a partly rivalrous public good, characterized by excludable benefits. Such goods are known as club goods.

There are a number of noteworthy reasons why club goods are different from pure public goods. First, the use of a club good is voluntary because sharers must join the club to receive the good's benefits, which are withheld from nonmembers. Despite fees, club members perceive a net gain from membership. For pure public goods, everyone within the range of spillovers automatically receives the good's benefit or cost. Second, the optimal number of sharers for club goods is finite unlike that of pure public goods, where everyone can be accommodated without crowding externalities. Clubs are, therefore, exclusive collectives. Third, for club goods, the disposition of nonmembers must be addressed. Multiple clubs form, where the population is partitioned into nonoverlapping identical clubs (McGuire 1974; Pauly 1967), or a single club forms, where leftover individuals do not consume the club good (Helpman and Hillman 1977). Fourth, club goods must possess an exclusion mechanism that is virtually costless, so that nonpaying individuals do not receive the good's benefits. This mechanism can collect tolls to finance the club good. In contrast, exclusion is not possible or desirable for a pure public good. Fifth, club goods involve a dual decision-the choice of provision and membership size. Only optimal provision is relevant for pure public goods. Sixth, unlike pure public goods, club goods are often optimally provided through congestion-internalizing tolls. In 
contrast, the Nash equilibrium associated with the private provision of pure public goods is typically suboptimal (Cornes and Sandler 1996). Seventh, club goods can be efficiently supplied through alternative institutional arrangements-e.g., member-owned clubs or for-profit firms.

Club goods do not represent all goods between the polar extremes of private goods and pure public goods. There is no linear scale between these two extremes, insofar as the properties of publicness really vary along two dimensions-rivalry and excludability. Moreover, club goods must possess some rivalry and sufficient excludability. Thus, public goods that are nonrivalrous but excludable-e.g., payper-view television programs-are not club goods, because the marginal cost of additional users is zero. As such, exclusion does not achieve efficiency (Sandler 2004). Public goods that are subject to crowding but cannot be excluded (e.g., some forms of information) are not club goods. This is also true of public goods whose exclusion cost overwhelms any efficiency gains, so that exclusion is not justified under current technological realties. Hence, club goods do not encompass all impure public goods, where benefits are partly excludable and/or partly rival. The key issue is that there exists a sufficiently inexpensive exclusion mechanism to charge users for the congestion that their use causes.

\section{Buchanan clubs}

\subsection{Mathematical representation}

The Buchanan (1965) model for clubs assumes two goods: a private numéraire good, $y$, and a club good, $X$. Club members possess not only identical tastes, but also the same resource or budget constraint. Each member utilizes the entire club good, so that $x^{i}=X$, where $x^{i}$ is the $i$ th member's club utilization. As such, each member's utilization of the shared good is fixed at its provision amount. There is costless exclusion, so that there is no transaction cost of any kind. In addition, there is no discrimination among members; hence, each member pays the same membership fee where club cost is shared among members. Clubs are replicable and partition the population into a set of clubs, each with the optimal number of members.

The utility function of member $i$ is

$$
U^{i}=U^{i}\left(y^{i}, X, s\right),
$$

where $\partial U^{i} / \partial y^{i}=U_{y}^{i}>0, \partial U^{i} / \partial X=U_{X}^{i}>0$, and $\partial U^{i} / \partial s=U_{s}^{i}<0$ for $s>\bar{s}$. Thus, utility increases with the consumption of the private and club goods, but decreases after some membership level, $\bar{s}$, with the number of members, $s$. Buchanan's formulation allows members to enjoy camaraderie up to point $\bar{s}$, but thereafter negative congestion externalities take over. This $\bar{s}$ can be anything greater or equal to zero, depending on the club good. For example, rock concerts can be more enjoyable until a certain crowd level is obtained, but after this level, toilets become crowded, noise competes with the musicians, views become obstructed, and parking becomes more 
difficult. For some venues, this $\bar{s}$ may be quite large, while for small intimate nightclubs, $\bar{s}$ may be as few as 10 people.

The $i$ th member's resource constraint is

$$
F^{i}\left(y^{i}, X, s\right)=0,
$$

where $\partial F^{i} / \partial y^{i}=F_{y}^{i}>0, \partial F^{i} / \partial X=F_{X}^{i}>0$, and $\partial F^{i} / \partial s=F_{s}^{i}<0$. At the margin, members must expend more resources for increases in the private and club goods; however, members must spend less for a given level of the club good as membership increases. This follows because more members can share the cost of the provision of the club good.

Each member chooses $y^{i}, X$, and $s$ to

$$
\max U^{i}\left(y^{i}, X, s\right) \text { subject to } F^{i}\left(y^{i}, X, s\right)=0 .
$$

The resulting first-order conditions can be rewritten as a provision and membership condition:

$$
\begin{aligned}
& M R S_{X y}^{i}=M R T_{X y}^{i}, \quad i=1, \ldots, s \text { (Provision) and } \\
& M R S_{s y}^{i}=M R T_{s y}^{i}, \quad i=1, \ldots, s \text { (Membership) }
\end{aligned}
$$

where $M R S_{X y}^{i}$ is the $i$ th member's marginal rate of substitution between the club good and the private good, and $M R T_{X y}^{i}$ is the $i$ th member's marginal rate of transformation between these goods. The former is a ratio of marginal utilities, while the latter is a ratio of resource marginal cost terms. In (5), the MRS and MRT have similar interpretations for the trade-off between membership size and the private good. Each of these conditions has a straightforward interpretation. For provision in (4), each member equates the marginal benefit of the club good, evaluated in terms of the numéraire, to the marginal cost of the club good. In the membership condition, members equate the marginal cost of an added member, which is the marginal crowding cost $\left(M R S_{s y}^{i}\right)$, to the marginal benefit of an added member, which is the marginal reduced cost of membership $\left(M R T_{s y}^{i}\right)$. Both of these terms are negative in the relevant range past $\bar{s}$.

These conditions embody some essential features. If, at the margin, the club is self-financing, then the sum of the members' marginal payments $\left(\sum_{i=1}^{s} M R T_{X y}^{i}\right)$ for provision must equal the club's marginal provision cost, $M R T_{X y}$, so that the provision condition in (4) then implies the Samuelsonian provision condition for public goods:

$$
\sum_{i=1}^{s} M R S_{X y}^{i}=M R T_{X y} .
$$

Full financing is achieved when $M R T_{X y}$ equals or exceeds average provision cost. The need to simultaneously satisfy both (4) and (5) indicates the dual decisions, mentioned in Sect. 2. That is, the optimal membership size, $s^{*}$, and the optimal provision, $X^{*}$, must be determined together. This stems from the provision and membership conditions containing both membership and the club good as 
arguments. By maximizing average net benefits for the representative member, the Buchanan model assumes away nonmembers, because replicable clubs accommodate the entire population. If the population size is denoted by Pop, then the number of replicable clubs is $P o p / s^{*}$, which is assumed to be an integer. When the homogeneous population is fully accommodated in the set of clubs, the solution is the core, because no alternative configuration of clubs can form and do better for its members (Pauly 1967; Sandler and Tschirhart 1980). In his original paper, Buchanan (1965) did not make the connection with the core, which came later as the literature developed his notion of clubs.

\subsection{Graphical representation}

The provision and membership conditions can be displayed graphically, thereby giving the reader a better appreciation for their dual nature. In Fig. 1, we display the optimizing club good provision levels for two alternative membership values. If membership is $s_{1}$, then $B\left(s_{1}\right)$ denotes the total benefit per member for alternative provision levels, while $C\left(s_{1}\right)$ depicts the total cost per member for alternative provision levels. The concavity of the benefit curve captures diminishing marginal benefits to increased provision; the linearity of the cost line reflects constant marginal provision cost. For membership $s_{1}$, optimal provision corresponds to $X_{1}^{*}$, where marginal provision benefit (the slope of the $B$ curve) equals marginal provision cost (the slope of the $C$ curve), so that (4) is satisfied. If, however, membership size increases to $s_{2}$, then the benefit curve shifts down, as shown in Fig. 1, so that, at each provision level, the reduced slope is due to increased crowding from enhanced membership and crowding. With more members, the cost line pivots down to $C\left(s_{2}\right)$ as each member needs to assume a smaller cost burden because there are more burden sharers. The optimal provision, associated with $s_{2}$, is $X_{2}^{*}$, where (4) is satisfied. Generally, as membership increases, the optimal provision level increases (Buchanan 1965), so that membership and optimal provision rise together. Later, we assume that they do so linearly for convenience.

Next, we depict the optimal club membership choice for two alternative provision levels in Fig. 2. We commence with the benefit and cost curves- $B\left(X_{1}\right)$ and $C\left(X_{1}\right)$, respectively - tied to provision level $X_{1}$ as membership varies. The benefit curve has an inverted U-shape: camaraderie increases marginal benefit up to a certain membership size, followed by declining marginal benefit owing to crowding as membership surpasses this threshold. The cost curve is a rectangular hyperbola, as the given cost of providing $X_{1}$ is spread over more members. As shown, the optimal membership $s_{1}^{*}$ for this provision level is achieved when the corresponding margins are equated to satisfy (5). An increase in provision to $X_{2}$ shifts up the benefit curve, which is now flatter at any given membership. This flattening captures the reduced marginal crowding cost that greater provision entails-e.g., more highway lanes mean that the same traffic can flow with less congestion. For $X_{2}$, the cost curve is displaced upward so that the slope has a larger absolute value at a given membership size. This follows because greater provision means that each member must assume a greater marginal cost burden. In Fig. 2, the 


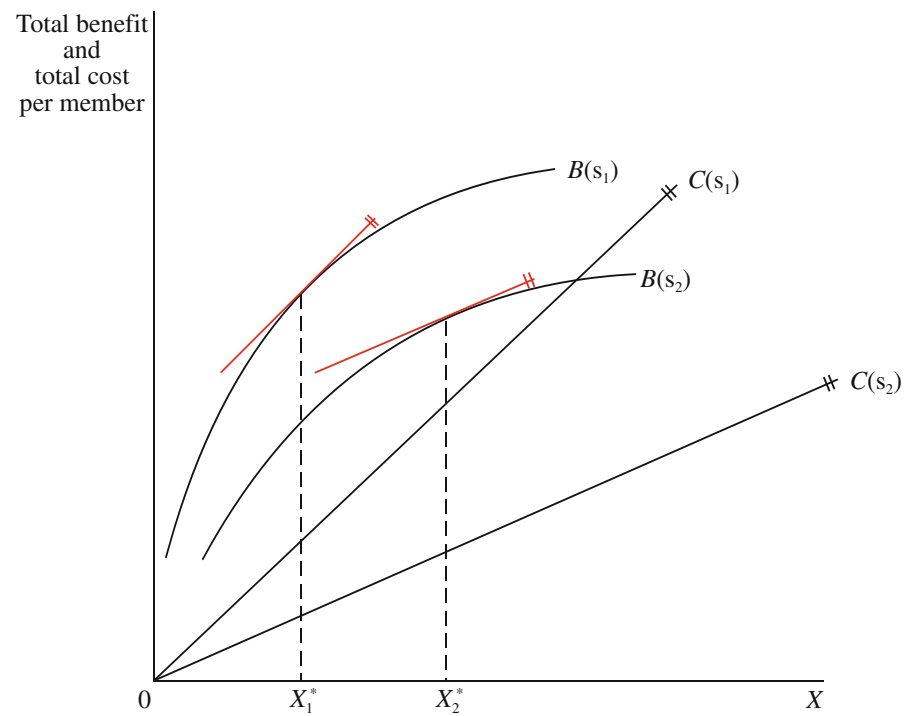

Fig. 1 Optimizing club good provision levels for two alternative memberships

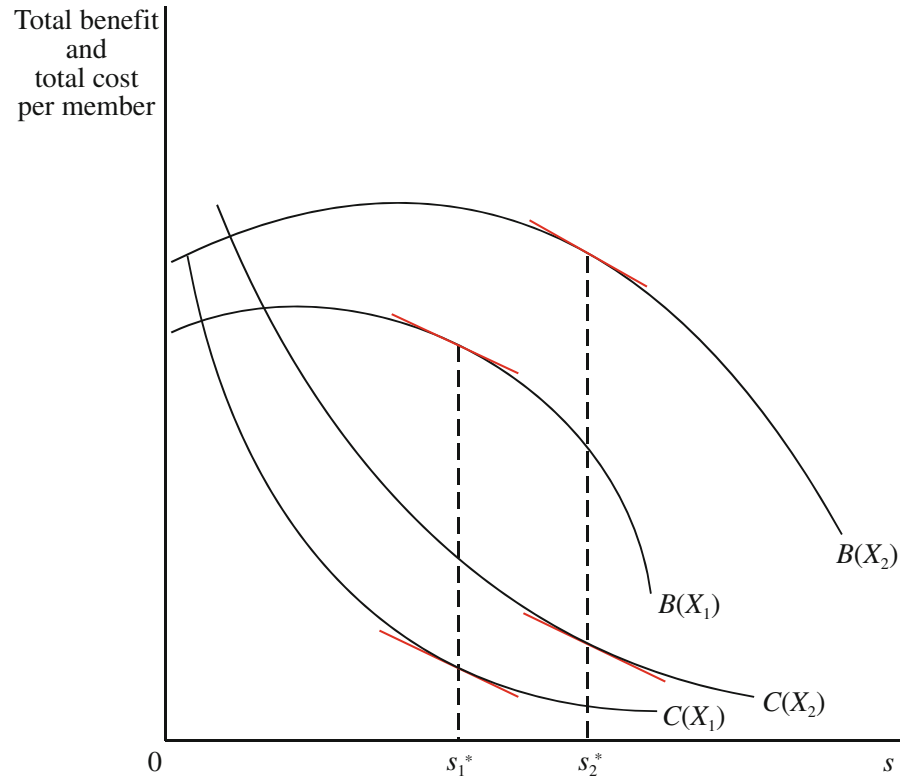

Fig. 2 Optimizing club membership for two alternative provision levels

optimal membership for $X_{2}$ is $s_{2}^{*}$, where (5) is again fulfilled. Optimal membership increases with augmented provision, whose relationship is assumed to be linear for simplicity in Fig. 3. 


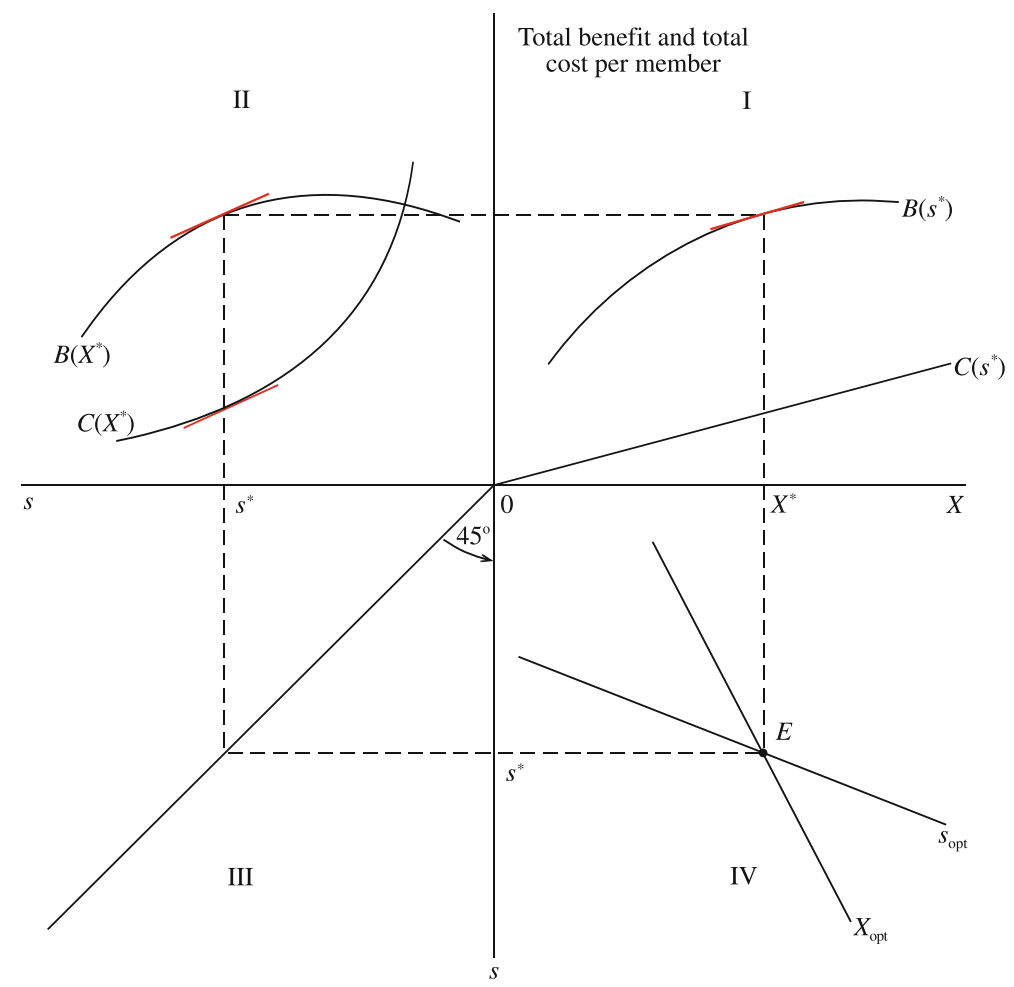

Fig. 3 Homogeneous club equilibrium

The four-quadrant Fig. 3 displays the club equilibrium for the two decision variables. Quadrant I depicts the optimal provision choice; quadrant II indicates the optimal membership choice; quadrant III transfer membership levels from the horizontal axis of quadrant II to the vertical axis of quadrant IV; and quadrant IV indicates stylized linear $s_{\text {opt }}$ and $X_{\text {opt }}$ loci. These loci relate optimal $s$ for alternative $X$ levels, and optimal $X$ for alternative $s$ levels. Their relative slopes are consistent with stable club equilibrium at $E$, where the two curves intersect.

Figure 3 lends itself to comparative statics. Suppose, for example, a technological advance that reduces provision cost, which, in turn, lowers the cost curves in quadrant I without affecting the benefit curves. This would then imply a rightward shift (not shown) in the $X_{\text {opt }}$ curve in quadrant IV, for which each membership size is now associated with a larger optimal provision level. This technological change also lowers and flattens the cost curves in quadrant II so that there is less need to spread cost over larger memberships. This, then, shifts $s_{\text {opt }}$ upward toward the horizontal axis in quadrant IV (not shown), so that each provision level is associated with a smaller optimal membership. In the new equilibrium, provision is apt to rise, while membership may rise or fall. The interface of the two decisions permit varied possibilities. 


\section{Some key variants of Buchanan clubs}

Buchanan (1965) presented a model that captures the essence of club theory, where the utilization rates of homogeneous members are fixed. The latter means that there is no rationale for distinguishing between membership fees and visitation tolls. In the ideal Buchanan club, each membership fee is $C / s$ or the club's cost per member, thereby ensuring full financing. For homogeneous clubs, there are two important variants of the Buchanan club model.

The McGuire (1974) model is quite streamlined and has members choosing $y^{i}, X$, and $s$ to

$$
\max U^{i}\left(y^{i}, X\right) \text { subject to } I^{i}=y^{i}+[C(X, s) / s],
$$

where $I^{i}$ is the income of the $i$ th member, the unit price of the private good is one, and $C(\cdot)$ is the cost of the club. This cost includes marginal provision cost, $C_{X}$, and marginal crowding cost, $C_{s}{ }^{2}$ The simplest way to derive the provision and membership requirements is to substitute for $y^{i}$ in the utility function, using the budget constraint. Optimizing this transformed utility function with respect to $X$ and $s$ gives:

$$
s M R S_{X y}^{i}=C_{X}
$$

and

$$
\left(s C_{s}-C\right) / s^{2}=0 \quad \text { or } \quad C_{s}=C / s .
$$

The provision condition in (8) is the standard Samuelsonian condition for public goods for identical individuals. Full financing of the club cost is embedded in the budget constraint in (7), where each identical member covers average cost of the club, $C / s$. In (9), the membership condition requires that marginal crowding cost, $C_{s}$, equals this average cost.

There are some noteworthy things about the McGuire model. First, the membership condition captures the Tiebout (1956) representation, in which per person average cost is minimized for the shared good. This, however, assumes that Tiebout jurisdictions are either providing a single local public good or else a package of local public goods that can be treated as a single entity in terms of crowding and provision. Second, the McGuire representation gives a specific form to Buchanan's resource constraint, where the cost function serves two purposes and full financing is assumed at the outset. Third, the collection of communities is each of size $s^{*}$, where $C_{s}=C / s$, is in the core, so long as $s^{*}$ divides evenly into the population. If, however, population were heterogeneous, then homogeneous jurisdictions must form, where each homogeneous subset of the population is partitioned into communities of size, $s_{i}^{*}$, which equals the optimal club size for $i$ type individuals (Pauly 1967). Fourth, McGuire (1974) demonstrated that his clubs cannot optimally accommodate different types of individuals. This follows because members must utilize the entire quantity of the club good. To accommodate

\footnotetext{
$\overline{2}$ Subscripts denote partial derivatives.
} 
different tastes, utilization patterns of members must be allowed to differ, which comes with more advanced models (see, e.g., Sandler 1984; Sandler and Tschirhart 1984; Scotchmer and Wooders 1987). Without this accommodation, McGuire correctly indicated that clubs must be segregated with identical members. So what has started as an innocuous assumption has become an implication that could mistakenly direct policy to segregate clubs. In the real world, most clubs do not require members with the same tastes or use patterns-e.g., some drivers use a bridge twice a day, while others may use it on rare occasions. Fortunately, later work allowed for heterogeneous members-see Sect. 5-and did not imply segregation or identical use patterns.

The second variant of the Buchanan model is by Berglas (1976), who allowed for variable utilization or visits, $v$, by members. The representative homogeneous member chooses $y^{i}, v, X$, and $s$ to

$$
\max U^{i}\left[y^{i}, v, c(X, s v)\right] \text { subject to } s I^{i}=s y^{i}+C(X, s v),
$$

where $c(\cdot)$ is the congestion function, which decreases with provision, $c_{X}<0$, and increases with total visits, $c_{s v}>0$. In the budget constraint, $C(\cdot)$ denotes club cost, where $C_{X}>0$ is the marginal provision cost and $C_{s v}>0$ is the marginal maintenance cost. The latter implies that greater overall use necessitates more cleanup. In the utility function, a member's satisfaction goes down with increased congestion, so that $U_{c}^{i}<0$. There are now three relevant conditions associated with (10), which includes provision, toll, and membership. The provision condition is again the Samuelsonian public good requirement with slightly different notation than in (8). The toll condition is as follows:

$$
C_{s v}-s c_{s v} M R S_{c y}=M R S_{v y}
$$

where the $i$ superscript has been dropped from the MRS because everyone is identical. ${ }^{3}$ In (11), the sum of marginal maintenance cost and marginal crowding cost $\left(-s c_{s v} M R S_{c y}\right)$ comprises the toll, $T$, which equals the member's marginal visitation benefit $\left(M R S_{v y}\right)$. Marginal crowding cost is summed over all members to internalize the crowding externality. ${ }^{4}$ The membership condition is not independent of the visitation condition, because it equals the visitation condition multiplied by $v$ on both sides (Cornes and Sandler 1996). Based on cost sharing in the budget constraint, the toll per visit is $C / s v$, where each member visits $v$ times and pays $\mathrm{C} / \mathrm{s}$ in total fees. The Berglas model adds two essential ingredients to Buchanan clubs: a congestion function and a visitation rate. These ingredients become more useful when heterogeneous members are allowed in subsequent articles. Berglas' concept of maintenance cost is also important because utilization may impose costs on members that go beyond congestion.

\footnotetext{
${ }^{3} M R S_{c y}=U_{c}^{i} / U_{y}^{i}$ and $M R S_{v y}=U_{v}^{i} / U_{y}^{i}$.

${ }^{4} M R S_{c y}$ is negative because crowding reduces utility.
} 


\section{A discussion of more general formulations}

\subsection{Heterogeneous memberships}

As an initial formulation of clubs, Buchanan (1965) was right to strip away complications by assuming homogeneous members. However, most real-world clubs-e.g., air traffic networks, Internet providers, communication systems, and those highlighted in Sect. 6-serve members, who possess dissimilar tastes and needs. These differences primarily manifest themselves in terms of varied utilization. An easy way to accommodate heterogeneous or "mixed clubs" is with a single club that serves a subset of the population, who are members (Artle and Averous 1973; Helpman and Hillman 1977; Sandler 1984). The optimal membership requirement distinguishes members from nonmembers; i.e., those individuals with the greatest willingness to pay join the club until membership charges outweigh membership benefits. This membership condition then distinguishes members from nonmembers. ${ }^{5}$ The toll condition is the key new ingredient for mixed clubs. All members pay the same congestion-internalizing toll when crowding is anonymous, ${ }^{6}$ but the total tolls paid by each member vary according to their revealed visits.

Consider Fig. 4 where Panel 1 displays the viewpoint of two members, $i=1,2$, and Panel 2 indicates the viewpoint of the club. The membership condition determines the number of members and, hence, the total number of visits, $V^{*}$, where the final entrant's downward-sloping marginal benefit for visits (not shown) equals the marginal crowding costs (shown in Panel 2). In Panel 2, this intersection, corresponding to $V^{*}$, then determines the toll, $T$, per visit. In Panel 1, two members' demands for visits $\left(M R S_{v y}^{i}, i=1,2\right)$ are displayed. Member 1 equates his demand to the equilibrium toll and makes $v^{1}$ visits at a cost of $v^{1} T$ in tolls, while member 2 equates her demand to the equilibrium toll and makes $v^{2}$ visits at a cost of $v^{2} T$. Thus, total tolls are individualized based on revealed use. Consider a toll road. Drivers' use of the road determines membership in practice. That is, drivers who do not gain sufficient convenience will not pay for the toll road, opting instead for a less convenient free highway.

Next, consider multiple clubs with differentiated club goods, such as Internet providers with different download speeds. Internet users will partition themselves into these providers according to their tastes for speed. Once users are partitioned, taste differences can again be accommodated based on user charges for the quantity of data downloaded. The beauty of clubs is that exclusion forces preference revelation, while congestion charges or tolls provide a basis for financing the shared good.

When members' attributes affect crowding, crowding is nonanonymous and tolls must be tailored to the user (DeSerpa 1977; Scotchmer 1997). Under these

\footnotetext{
5 The sequence of joiners should be based on their willingness to pay, with those with greater willingness to pay joining first. That is, the joining sequence is ordered by the willingness to pay.

${ }^{6}$ Crowding is anonymous when each visit causes the same congestion regardless of the visitor. That is, the attributes of the visitor do not affect the amount of crowding.
} 


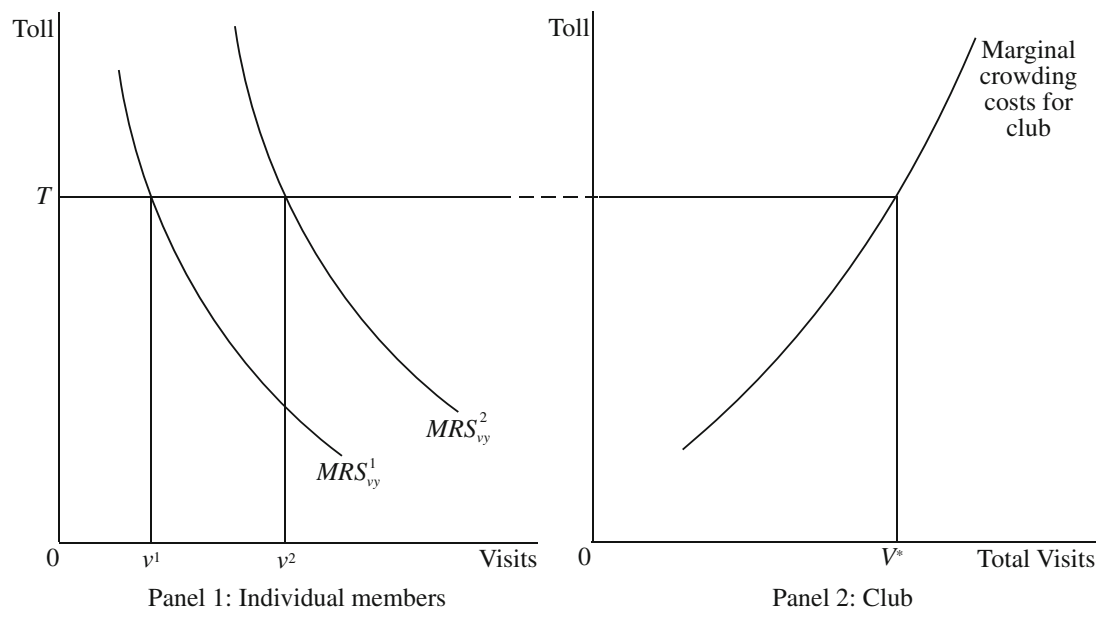

Fig. 4 Individualized toll payments in a club

circumstances, club design becomes more difficult. Consider a learned society. Really smart or accomplished members may offer more positive externalities from their presence than any crowding that they cause, so that their membership fee or toll may be negative, resulting in a subsidy! Most members of the society have to pay tolls because their crowding dominates. In some clubs, the refinement of the notion of a visit may be a more practical means to account for nonanonymous crowding. Consider a golf course where some golfers cause more crowding per round than others. If the unit of utilization (a round of golf) were redefined by the number of strokes taken, then crowding becomes essentially anonymous. This follows because the number of strokes is a better indicator than a round of golf of the crowding externality that one golfer imposes on other golfers. Golf courses can also cater to different skilled players by their toughness of play (e.g., length of holes, width of fairways, and the number of hazards), where presumably the better golfers will play (join) the harder courses. Thus, even nonanonymous crowding can sometimes be circumvented through provision decisions (i.e., club goods tailored to the members' attributes) or finer utilization measurement. In the golf example, this circumvention does not work for, say, Tiger Woods, for whom other golfers would pay dearly to have on their course.

\subsection{Congestion function}

In the Buchanan (1965) article, the congestion function was just the identity map applied to the number of members. The congestion function can, however, assume many forms to capture the nature of a particular shared good. For example, it can depend on the average utilization rate, which is the total number of visits divided by provision. The actual form of the congestion function is important for at least two reasons: (1) it helps determine the toll and (2) it affects whether efficient tolls can self-finance optimal provision of the club good (Oakland 1972; Sandler 1982). By 
affecting the amount of marginal crowding cost, the congestion function influences the toll. For highways, a congestion function that is homogeneous of degree zero in total utilization and provision is associated with tolls that self-finance efficient provision $^{7}$ (Cornes and Sandler 1996, 272-277.). If the congestion function depends on the average utilization of the club good, then this function is homogenous of degree zero and self-finance results. If congestion is not homogeneous of degree zero, then crowding-internalizing tolls may collect too little or too much to finance the club good (Oakland 1972; Sandler and Tschirhart 1980).

The form of the congestion function is important in urban economics when designing cities, infrastructure, and highways. Civil engineers can design highways that allow for better traffic flows, where a given amount of cars and trucks can be accommodated with less crowding. For airports, the spacing of take-offs and landings can make for a more favorable congestion relationship. The design of health clinics also determines the length of the queue or the resulting crowding. Since the congestion function may be tied to the amount of provision, we again see how provision and tolls are a dual decision.

The ability to monitor and charge for congestion is tied to the exclusion mechanism. These mechanisms can allow for fine exclusion, where each visit is monitored and a toll levied, or coarse exclusion, where only a membership fee is charged (Helsley and Strange 1991). Coarse exclusion results in inefficiency, since members will visit until their marginal benefit from visiting is driven to zero (Berglas 1976). Fine exclusion does not result in inefficiency, because per visit tolls internalize the associated congestion cost for every visit. In practice, clubs may resort to coarse exclusion if the transaction cost associated with fine exclusion more than offsets the efficiency gain.

\subsection{Institutional forms of clubs}

Buchanan (1965) only considered member-owned and operated clubs. There is, however, no reason why firms cannot provide clubs-e.g., movie theaters and athletic clubs. Many toll roads are now provided by private firms. Berglas and Pines (1981) demonstrated that firms in a competitive industry can also achieve the same equilibrium as a set of Buchanan replicable clubs, where population is a integer multiple of the optimal club size, $s^{*}$. For simplicity, potential members are again assumed to possess the same tastes and endowments. Each firm maximizes its profit subject to a utility constraint for the members. The profit is the difference between revenues from tolls minus the cost of club provision and maintenance, while the utility constraint requires members to achieve at least the same utility, $U^{*}$, as with a member-owned club. ${ }^{8}$ The firm's optimization results in the same provision, toll, and membership conditions, previously associated with (10) (Cornes and Sandler 1996, 395-397). In the firm's problem, each member pays a per visit toll equal to $\mathrm{Clsv}$.

\footnotetext{
7 Homogeneous of degree zero means that equal proportional changes to total utilization and provision do not alter the level of congestion.

${ }^{8}$ Each firm faces the following problem: $\max [s v T-C(X, s v)]$ subject to $U[I-v T, v, c(X, s v)] \geq U^{*}$.
} 
There is also the possibility of government-provided clubs. For example, the federal government provides national parks, and state governments supply state parks. In many such cases, an entrance or user fee is charged. When crowding causes permanent degradation to the park, admittance is stopped for the day. For some popular national parks, a lottery system is now used during peak periods to limit degradation. If the government can charge congestion-internalizing tolls, then a government can also provide and manage club goods efficiently. At the local level, governments often rely on property taxes to finance the club good. These taxes may not really reflect crowding and utilization, thereby creating inefficiency. As an institutional alternative, government-managed clubs fail when they do not properly internalize crowding. Unlike other institutional forms, government-managed clubs may face more pricing or membership constraints-e.g., the use of coarse exclusion or the requirement to serve everyone (i.e., a public-access requirement).

There are other institutional form questions concerning clubs. For example, is there a difference between for-profit and not-for-profit clubs in terms of efficiency? This question has not been fully addressed but hinges on two considerations: (1) differences in transaction cost and (2) differences in internalizing the crowding externality. In the literature, there is no transaction cost distinction between for-profit clubs and memberowned clubs even though differences surely exist. Also, the ability of these clubs to distinguish between utilization rates may also differ according to institutional form, since member-owned clubs may favor coarse over fine exclusion. Another institutional question concerns multiproduct clubs, where multiple club goods are shared by the same membership. The notion of economies of scope ${ }^{9}$ looms large in the analysis of such clubs (Brueckner and Lee 1991). Multiproduct club theory could serve as a better foundation for the Tiebout hypothesis, since jurisdictions offer an array of shared goods-e.g., highways, city hall, fire department, and police force. With economies of scope, the need to minimize average cost per member will lose its sway because this is a single-product concept and does not account for cost interaction among club goods. Moreover, shared club goods may appeal to different subsets of members (residents), which results in the need for efficiency trade-offs. A third institutional question involves distinguishing between different classes of memberse.g., first-class and coach passengers on an airplane. In some ways, this issue can be subsumed in the notion of a multiproduct club, where the classes of services are effectively different club goods, where different fees distinguish the two classes of services and members are partitioned between the classes. This example offers an important insight: the study of clubs can be pushed forward by combining insights and methods from earlier models.

\section{Applications of club theory}

Perhaps, the greatest testimony of the importance of Buchanan's analysis of clubs is reflected in the many and varied applications of the theory. This section provides a

\footnotetext{
${ }^{9}$ Economies of scope arise when providing two or more club goods jointly in the same club is less expensive than supplying them in separate clubs owing to shared common costs.
} 
small sampling of these applications, most of which involve extensions to Buchanan's original formulation to allow heterogeneous tastes and complex congestion and cost relationships.

Although jurisdictional design (Tiebout 1956) predated Buchanan's (1965) study on clubs, the latter article provided the theoretical foundation for this design (McGuire 1974). In so doing, many questions were raised including whether individual choice would necessarily internalize the crowding externality as people voted with their feet to find their ideal tax/public good package. Problems may arise because an individual's decision to join a jurisdiction did not always account for the crowding consequences that this choice imposed on the existing residents of the jurisdiction. Another question concerned the need for homogeneous jurisdictions because everyone consumed the same provision package. The partitioning of the population among a set of nonoverlapping jurisdictions resulted in a pioneering application of game theory to the study of public goods, since the notion of the core became relevant (Pauly 1967).

Another key application of club theory involved highway pricing, provision, and financing (Mohring and Harwitz 1962; Vickrey 1969). The reason why tolls can be used to provide highways efficiently is because any transit, beyond some minimal level of use, has a nonzero marginal cost owing to crowding. Thus, the practice of exclusion can serve to internalize an externality. The real question then becomes whether this toll can self-finance optimal provision without the need for subsidies. As mentioned earlier, this question hinges on the forms of the congestion and cost functions. If, for example, the cost function displays decreasing cost, then marginal cost financing will not fully cover the club good's cost and a two-part tariff is needed to make up the difference (Sherman 1967). One part is the user toll and a second part is a membership fee to cover the shortfall. The two-part tariff is particularly germane to urban transportation systems-e.g., commuter trainswhere scale economies are present.

Club theory is also applicable to recreation areas. For a given wilderness capacity or area, Fisher and Krutilla (1972) determined membership size to equate the associated marginal cost and marginal benefit from the experience. These authors then focused on joining the membership and capacity (provision) decision along the lines of Fig. 3. Cicchetti and Smith (1973) later determined the optimal utilization or membership for low-density, fixed-capacity wilderness areas by adjusting for congestion in the form of trail encounters. These authors used questionnaires, distributed to hikers, to ascertain the congestion relationship and the setting of user fees.

Artle and Averous (1973) investigated the telephone system as a club good. Their theoretical representation maximized the net benefits of both subscribers and nonsubscribers, thereby deriving the Pareto optimality conditions for a single economy-wide club. The telephone system is a particularly interesting club since it possesses not only negative crowding, but also positive network externalities. Both of these opposing externalities must be taken into account when ascertaining membership, toll, and provision (Squire 1973; von Rabenau and Stahl 1974). Network externalities require membership well beyond that when there are just crowding externalities. 
Olson and Zeckhauser (1966) introduced military alliances as sharing a pure public good-i.e., deterrence. This representation may have applied to the early years of NATO, when allies relied on deterrence primarily provided by US strategic weapons (Sandler and Hartley 2001). In contrast, Sandler (1977) described a conventional alliance as a club, for which protecting a potential front or perimeter is a club good, subject to the thinning of forces (Sandler and Forbes 1980). As such, club principles can be applied to ascertain the optimal alliance size and user fees. For NATO, shared defense gave rise to joint products in the form of purely public deterrence, impurely public front protection, and ally-specific benefits (e.g., disaster relief and putting down local unrest). ${ }^{10}$ Sandler (1977) derived optimality conditions in light of these joint products. Membership restriction and tolls are only relevant for shared protection. Without joint products, optimality hinges on the share of excludable benefits. As this share approaches one, optimality is more assured as markets and thinning charges force preference revelation for country-specific and excludable impure benefits, respectively. Thus, club principles can be applied to some components of joint products. ${ }^{11}$

A novel club application involves the International Telecommunications Satellite Organization (INTELSAT), which is now a private company that links much of the world in an external communication network. Originally, the system consisted of geostationary satellites positioned some 22,300 miles over the equator. At that altitude, satellites remained essentially fixed over a point on the earth's surface. Sandler and Schulze (1981) showed how to allocate geosynchronous orbits and its complementary electromagnetic bandwidth in a club arrangement that accounted for two crowding phenomena: (1) signal interference owing to transmissions and (2) satellite collision owing to satellite drift. User tolls, based on signals sent and received, internalize the first externality, while fees for "parking spaces" in geostationary orbit internalize the second externality. User revenues finance the system and its upgrades. The provision decision concerns the number of satellites and their communication capacity.

Intergenerational clubs apply to a wide range of club goods-e.g., antibiotics, the stratospheric ozone layer, cities, planet Earth, cathedrals, and national parks. Multiple generations of members share the club good, which is subject to atemporal crowding and intertemporal depreciation. Depreciation implies the degradation of the club good due to use-e.g., bridge or airplane fatigue. If a toll is to self-finance the intergenerational club good, then the toll must internalize both crowding and depreciation. Maintenance now assumes an intertemporal dimension because it involves repairs to extend the shared good's lifetime. Also, membership span needs to be determined. Sandler (1982) demonstrated that self-financing now requires bonds, equities, or some leveraged combination of the two, which are supported

\footnotetext{
10 Joint products also apply to "green clubs," where members receive excludable reputation benefits for participating and pure public benefits from generating environmental improvements (van't Veld and Kotchen 2011).

11 Another joint-product example with purely public, impurely public, and country-specific private benefits is the Amazon jungle (Sandler 2004). For example, the sequestration of carbon and the housing of unique species are purely public, while ecotourism is a club good. Harvested fruits and nuts are private benefits.
} 
through toll collection. Myopic toll collection becomes a relevant concern along with suboptimal maintenance. The latter arises because maintenance is purely public to the members, thereby leading to free-rider concerns. This worry may be internalized when members realize that, when they sell their ownership share to the next generation, inadequate maintenance will result in lower resale values.

Club theory even has a place in the modern analysis of terrorism. Sandler et al. (1983) characterized commando squads, used to address terrorist incidents, as providing crisis management and damage-limiting capabilities, whose benefits are excludable and subject to crowding. These squads can be provided by a collective of at-risk countries, which then charge for their deployment to specific terrorist events. Moreover, commando squads can be optimally positioned around the globe to allow for reasonably fast arrival for specific incidents. Sharing such squads provide cost savings to governments by eliminating duplicate squad that may be engaged infrequently. Despite this economic rationale, most governments maintain their own squads. From the terrorist's viewpoint, terrorist groups (e.g., Hezbollah and Hamas) may supply excludable club goods (e.g., health care, education, and social welfare) to recruit suicide bombers to hit hardened targets (Berman and Laitin 2008). These terrorist groups utilize these club goods to eliminate potential defection of bombers, whose families would be subsequently excluded from the goods' benefits. Would-be bombers are showered with club benefits, which can include camaraderie and prestige.

Canals, interregional highways, and power grids are a few examples of regional club goods (Estevadeordal et al. 2004). Initial provision of such regional club goods poses a problem, because a regional collective must form and possess the means to provide an expensive good. In some instances, these goods may be financed by regional collectives that draw funds from leading regional nations, regional development banks, the World Bank, and customs unions. Repayment of loans can come from congestion-internalizing tolls. The rise of regionalism makes these regional club goods of greater importance.

Treaties for common pollution problems are clubs. Earlier, the stratospheric ozone layer was described as an intergenerational club good. Thus, the Montreal Protocol and its amendments provide a club good to ratifying nations (Congleton 1992; Murdoch and Sandler 1997). At a regional level, treaties limiting acid rain represent regional clubs. Murdoch et al. (1997) investigated the ratification and adherence to the Helsinki and Sofia Protocols regarding sulfur and nitrogen oxides pollutants, respectively. Both of these pollutants display deposition rivalry as particles drift downwind. Nations that receive greater shares of these depositions have been shown to be more willing to ratify the treaty (Murdoch et al. 1997).

\section{Concluding remarks}

A Buchanan club is a decentralized, voluntary organization sharing an impure public good that is excludable and congestible. In its ideal form, clubs operate without transaction cost and can be replicated to partition a homogeneous population. Because all members possess the same tastes and endowments, no 
centralized control is needed. Buchanan's (1965) stripped-down formulation captured the essence of clubs and served as an ideal platform for myriad extensions.

Buchanan's (1965) theory of clubs offered a number of seminal ideas. First, this theory showed that club goods can be privately supplied, provided that nonmembers can be costlessly excluded. Second, club goods concerned two interrelated choices that involve membership and provision. As club theory was extended, more interrelated decisions became relevant (e.g., the number of clubs). Third, clubs permit preference revelation through visits that can be monitored; hence, total toll charges can differentiate among members' tastes. That is, heavier users paid more in total tolls, but everyone paid the same toll per visit. Fourth, Buchanan's club framework provided for the first explicit marrying of game theory and the study of public goods. Fifth, club theory offered a theoretical foundation for jurisdictional design. Sixth, club principles are applicable to myriad goods.

Technology and innovations are continually providing more club goods. Noteworthy recent examples include the Internet, flight paths, satellite television, the international space station, and reusable suborbital spacecraft. Other club goods, unimaginable today, will come to dominate our lives. In addition, technology will continue to reduce the cost of exclusion, thereby satisfying the crucial costless exclusion assumption in the Buchanan (1965) article. For example, toll booths are no longer required on highways owing to remote ways to count passages and to charge accordingly. Some nonexcludable public goods will become club goods due to technological advances in monitoring. As such, the realm of club goods will grow as a subset of public goods. As clubs become more prevalent, new problems will surface and have to be addressed. These problems include the dynamic growth of membership over time. Another problem involves the need for surge capacity to accommodate members during peak usage. Currently, this can be addressed through tolls that vary based on usage rates. Nevertheless, there will be times of gridlock or when members are denied entry. Only a couple of articles have addressed this issue (see, e.g., Sandler et al. 1985).

Except for work on fine versus coarse exclusion, the institutional form of clubs has not been analyzed. Moreover, member-owned and firm-owned clubs are treated as having the same transaction cost. Thus, there are many areas of clubs that can use further investigation.

Acknowledgments The author profited from comments from an anonymous referee and Roger Congleton on earlier drafts. Sandler's research was partly supported by the Vibhooti Shukla endowment.

Open Access This article is distributed under the terms of the Creative Commons Attribution License which permits any use, distribution, and reproduction in any medium, provided the original author(s) and the source are credited.

\section{References}

Artle, R., \& Averous, C. P. (1973). The telephone system as a public good: Static and dynamic aspects. The Bell Journal of Economics, 4, 89-100. 
Berglas, E. (1976). On the theory of clubs. The American Economic Review, 66, 116-121.

Berglas, E., \& Pines, D. (1981). Clubs, local public goods and transportation models: A synthesis. Journal of Public Economics, 15, 141-162.

Berman, E., \& Laitin, D. D. (2008). Religion, terrorism and public goods: Testing the club model. Journal of Public Economics, 92, 1942-1967.

Brueckner, J. K., \& Lee, K. (1991). Economies of scope and multiproduct clubs. Public Finance Quarterly, 19, 193-208.

Buchanan, J. M. (1965). An economic theory of clubs. Economica, 32, 1-14.

Cicchetti, C. J., \& Smith, V. K. (1973). Congestion, quality deterioration, and optimal use: Wilderness recreation in the Spanish Peaks primitive area. Social Sciences Research, 2, 15-30.

Congleton, R. D. (1992). Political institutions and pollution control. The Review of Economics and Statistics, 74, 412-421.

Cornes, R., \& Sandler, T. (1996). The theory of externalities, public goods, and club goods. New York, NY: Cambridge University Press.

DeSerpa, A. C. (1977). A theory of discriminatory clubs. Scottish Journal of Political Economy, 24, 33-41.

Estevadeordal, A., Frantz, B., \& Nguyen, T. R. (Eds.). (2004). Regional public goods: From theory to practice. Washington, DC: Inter-American Development Bank and Asian Development Bank.

Fisher, A. C., \& Krutilla, J. V. (1972). Determination of optimal capacity of resource-based recreational facilities. Natural Resources Journal, 12, 417-444.

Helpman, E., \& Hillman, A. L. (1977). Two remarks on optimal club size. Economica, 44, 293-296.

Helsley, R. W., \& Strange, W. C. (1991). Exclusion and the theory of clubs. Canadian Journal of Economics, 24, 888-899.

McGuire, M. C. (1974). Group segregation and optimal jurisdictions. Journal of Political Economy, 82, $112-132$.

Mohring, H. D., \& Harwitz, M. (1962). Highway benefits: An analytical review. Evanston, IL: Northwestern University Press.

Murdoch, J. C., \& Sandler, T. (1997). The voluntary provision of a pure public good: The case of reduced CFC emissions and the Montreal Protocol. Journal of Public Economics, 63, 331-349.

Murdoch, J. C., Sandler, T., \& Sargent, K. (1997). A tale of two collectives: Sulphur versus nitrogen oxides emission reduction in Europe. Economica, 64, 281-301.

Oakland, W. H. (1972). Congestion, public goods, and welfare. Journal of Public Economics, 1, 339-357.

Olson, M. (1965). The logic of collective action. Cambridge, MA: Harvard University Press.

Olson, M., \& Zeckhauser, R. (1966). An economic theory of alliances. The Review of Economics and Statistics, 48, 266-279.

Pauly, M. V. (1967). Clubs, commonality, and the core: An integration of game theory and the theory of public goods. Economica, 34, 314-324.

Sandler, T. (1977). Impurity of defense: An application to the economics of alliances. Kyklos, 30, 443-460.

Sandler, T. (1982). A theory of intergenerational clubs. Economic Inquiry, 20, 191-208.

Sandler, T. (1984). Club optimality: Further clarifications. Economics Letters, 14, 61-65.

Sandler, T. (2004). Global collective action. New York, NY: Cambridge University Press.

Sandler, T., \& Forbes, J. F. (1980). Burden sharing, strategy, and the design of NATO. Economic Inquiry, $18,425-444$.

Sandler, T., \& Hartley, K. (2001). Economics of alliances: The lessons for collective action. Journal of Economic Literature, 39, 869-896.

Sandler, T., \& Schulze, W. (1981). The economics of outer space. Natural Resources Journal, 21, 371-393.

Sandler, T., Sterbenz, F., \& Tschirhart, J. T. (1985). Uncertainty and clubs. Economica, 52, 467-477.

Sandler, T., \& Tschirhart, J. T. (1980). The economic theory of clubs: An evaluative survey. Journal of Economic Literature, 18, 1481-1521.

Sandler, T., \& Tschirhart, J. T. (1984). Mixed clubs: Further observations. Journal of Public Economics, 23, 381-389.

Sandler, T., \& Tschirhart, J. T. (1997). Club theory: Thirty years later. Public Choice, 93, 335-355.

Sandler, T., Tschirhart, J. T., \& Cauley, J. (1983). A theoretical analysis of transnational terrorism. American Political Science Review, 77, 36-54.

Scotchmer, S. (1997). On price-taking equilibrium in club economies with nonanonymous crowding. Journal of Public Economics, 65, 75-88. 
Scotchmer, S., \& Wooders, M. H. (1987). Competitive equilibrium and the core in club economies with anonymous crowding. Journal of Public Economics, 34, 159-173.

Sherman, R. (1967). Club subscriptions for public transport passengers. Journal of Transportation and Economic Policy, 1, 237-242.

Squire, L. (1973). Some aspects of optimal pricing for telecommunications. The Bell Journal of Economics, 4, 515-525.

Tiebout, C. M. (1956). A pure theory of local expenditures. Journal of Political Economy, 64, 416-424.

van't Veld, K., \& Kotchen, M. J. (2011). Green clubs. Journal of Environmental Economics and Management, 62, 309-322.

Vickrey, W. S. (1969). Congestion theory and transport investment. The American Economic Review, 59, 251-260.

von Rabenau, B., \& Stahl, K. (1974). Dynamic aspects of public goods: A further analysis of the telephone system. The Bell Journal of Economics, 5, 651-659.

Wiseman, J. (1957). The theory of public utility price-An empty box. Oxford Economic Papers, 9, $56-74$. 